\title{
Documentos convencionais e não convencionais em administração, ciências contábeis e economia: estudo sobre sua utilização pelos alunos de graduação
}

Pedro Luiz Côrtes

Doutor em Ciências da Comunicação pela Universidade de São Paulo. Pós-Doutor pela Universidade de São Paulo. Professor da Escola de Comunicações e Artes daUSP e da Escola Superior de Engenharia e Gestão - ESEG

Dinah Aguiar Población

Doutora em Ciências da Comunicação pela Universidade de São Paulo. Pós-Doutora pela Universidad Autonoma de Madrid. Professora da Escola de Comunicações e Artes da USP

Dentre as fontes de referências bibliográficas recomendadas para o desenvolvimento de trabalhos científicos, estão os textos submetidos a uma avaliação sob a forma de peer-review. Em que pese essa recomendação, verifica-se o uso cada vez mais freqüente, por parte dos alunos de graduação, de documentos não convencionais. Desenvolvida na forma de um survey, com 145 alunos de Administração, Ciências Contábeis e Economia, esta pesquisa caracteriza esse uso e prospecta estratégias de ensino apoiadas no uso de documentos não convencionais.

Palavras-Chave: Documentos não convencionais; educação; Fontes de referência; Estratégias de ensino. 


\title{
The use of conventional and non conventional bibliography in administration, accounting and economics: a research with undergraduate students.
}

\begin{abstract}
The recommended bibliographical references for the development of scientific research are those published by scientific journals. In spite of this recommendation, the use of non conventional documents by undergraduate students has been increasing. This paper, developed as a survey with 145 students of Administration, Accounting and Economics, characterizes the use these documents and analyzes teaching strategies supported in the use of non conventional documents.
\end{abstract}

Keywords: Not conventional documents; Bibliographies references; Education; Strategies of teaching.

Recebido em 10.07.2009

Aceito em 04.12.2009

\section{Introdução}

Os documentos tradicionalmente utilizados e recomendados para o desenvolvimento de pesquisas e trabalhos científicos são constituídos de textos que, antes de sua publicação, devem ter sido submetidos a uma avaliação prévia sob a forma de peer-review. Esses sistemas geralmente consistem na utilização de dois ou mais pareceristas especializados que avaliam aspectos diversos do texto (tais como bibliografia utilizada, metodologia adotada e interpretação dos resultados obtidos). Essas formas de avaliação, usualmente utilizadas pelas revistas científicas, têm como objetivo garantir a qualidade dos textos publicados, constituindo importante subsídio aos autores e editores, em face das recomendações e sugestões efetuadas.

Esse cuidado maior na avaliação e seleção de textos submetidos à publicação faz com que os docentes recomendem aos seus alunos o uso de artigos publicados em revistas científicas, como subsídio à realização de trabalhos acadêmicos ou como reforço de conteúdos apresentados em sala de aula. Apesar dessa recomendação, verifica-se o crescimento do uso de documentos considerados não convencionais (também denominados de literatura cinzenta no âmbito das Ciências da Informação), como relatórios de pesquisa, relatórios técnicos, documentos governamentais, textos disponíveis na Internet, entre outros. 
Há que se ressaltar que essas fontes alternativas geralmente não sofrem o mesmo fluxo no processo de análise e rigorosa avaliação preliminar dos pares, como ocorre com os artigos publicados nas revistas científicas, o que pode comprometer a qualidade dos conceitos e informações apresentados. Por outro lado, é importante considerar que esse tipo de documento pode constituir-se, por vezes, na única fonte primária disponível sobre determinados assuntos ou temas emergentes, ampliando a importância do seu estudo nas Ciências Sociais Aplicadas.

Com o uso cada vez mais intenso da Internet, crescem as facilidades de publicação e utilização de textos diversos, contribuindo para uma rápida difusão de conceitos, idéias e proposições, que resultam de pesquisas e indicadores setoriais, embora se deva considerar a ausência de um controle de qualidade eficaz, pelo menos para uma parte dos textos disponíveis. Essa facilidade tem levado os alunos de graduação ao uso mais intensivo de textos publicados fora dos canais usuais de difusão científica, conforme observado por Parreiras et al. (2006) e Côrtes (2006).

Como a publicação de artigos científicos geralmente demanda um tempo maior do que aquele empregado na elaboração de relatórios técnicos ou no preparo de matérias de cunho jornalístico, assuntos emergentes acabam sendo divulgados com antecedência pelos canais não acadêmicos, tais como jornais, revistas de divulgação e sites de conteúdo diverso. Desta forma, podem constituir, conforme a conveniência e necessidade do professor, material didático suplementar para uso em sala de aula ou subsídio ao estudo de temas mais específicos. Soma-se a isso o fato já mencionado de que, por vezes, esses textos não convencionais ao ambiente acadêmico são a única fonte primária de informação disponível sobre determinados temas, ampliando a importância da discussão sobre seu uso no âmbito das Ciências Sociais Aplicadas.

Essas formas de comunicação não apenas tornam mais rápido o acesso aos resultados de pesquisas, relatórios, estudos e análises, como também criam situações antes não verificadas em meios mais convencionais. Justifica-se essa pesquisa em razão do uso crescente de textos e informações disponibilizados fora dos canais convencionais de comunicação científica. Acredita-se que seja importante para docentes e pesquisadores estabelecer melhor entendimento do tema, possibilitando uma orientação aos alunos quanto ao uso da literatura cinzenta e prospectando usos didáticos para essas fontes de informação.

Considerando essa perspectiva, foi desenvolvida uma pesquisa com o objetivo de trazer à discussão alguns aspectos relacionados ao uso de fontes não convencionais pelos alunos dos cursos mencionados, fornecendo elementos que possibilitem maior entendimento e compreensão deste tema. Para atender a esse objetivo, foi desenvolvida uma pesquisa do tipo survey, com uma população composta por alunos do último ano de graduação dos cursos de Administração de Empresas, Ciências Contábeis e Economia, do período noturno, de uma única instituição de ensino superior, de caráter privado, localizada na cidade de São Paulo. 
Mais especificamente, partindo do pressuposto de que os alunos de graduação são usuários mais freqüentes de fontes de informações não convencionais (literatura cinzenta e material jornalístico ou de divulgação) do que de trabalhos científicos, o problema que se apresenta é: "quais documentos não convencionais são mais utilizados pelos alunos de graduação em Administração, Ciências Contábeis e Economia e como eles são avaliados por esse grupo?".

\section{Revisão da literatura}

Para subsidiar o desenvolvimento desta pesquisa, o levantamento bibliográfico foi efetuado em duas vertentes. Inicialmente, buscou-se caracterizar as diferenças entre a literatura branca e cinzenta (dentro da área das Ciências da Informação), incluindo algumas considerações sobre a evolução desses termos. Posteriormente, foram pesquisados atributos que pudessem ser utilizados para melhor qualificar as fontes de informação (jornais, revistas e sites, por exemplo) e os seus produtos (fundamentalmente, textos e informações disponibilizados).

A revisão da literatura auxiliou tanto o desenvolvimento do survey, fornecendo elementos para a elaboração do instrumento de pesquisa e seleção das publicações analisadas, quanto a interpretação dos resultados obtidos.

\subsection{A literatura branca e cinzenta}

Ao longo da vida acadêmica, os alunos de graduação são instruídos quanto ao uso, em seus trabalhos e pesquisas, de referências obtidas em revistas científicas, exatamente por serem publicações cujos critérios de aceitação garantem uma qualidade adequada em relação à metodologia utilizada e aos conceitos emitidos. No contexto das Ciências da Informação, essas fontes são habitualmente chamadas de literatura branca (PARREIRAS et al., 2006; CÔRTES, 2006; CORREIA, 2001; CORREIA; BORBINHA, 2001). Este é um movimento que teria o seu início remotamente ligado à Revolução Industrial, intensificando-se até a Segunda Guerra Mundial, sendo essa classe de documentos denominada "literatura de informes" (CARVALHO, 2001). Com a Segunda Guerra, o grande esforço empreendido pelos Estados Unidos, Inglaterra e Alemanha levou a um aumento considerável na quantidade de pesquisas em diversas áreas do conhecimento. A urgência da guerra demandava rapidez na publicação dos resultados entre cientistas e centros de pesquisa. Essa tendência se manteve no pós-guerra, especialmente em pesquisas relacionadas ao uso da energia nuclear e avanços tecnológicos.

$\mathrm{Na}$ década de 1970, o tipo de material constituído por relatórios, resumos, pareceres, anotações e artigos, publicados na forma de preprints e disponibilizados fora dos canais formais de difusão científica, passou a ser denominado, com maior freqüência, de literatura cinzenta. A expressão, originalmente cunhada no final do século XIX, está associada ao costume europeu de dar nomes de cores a diferentes tipos de 
documentos (CARVALHO, 2001). Esse amplo conjunto é estudado pelas Ciências da Informação, verificando-se um crescimento das pesquisas sobre este tema nos últimos anos (FUNARO; NORONHA, 2006; WEBSTER, 2004; PACE, 2002).

Para melhor entendimento do termo "literatura cinzenta", é interessante verificar algumas definições adicionais. Perez Álvares-Ossorio (1988), adotando uma definição mais ampla, considera como literatura cinzenta o conjunto de documentos dos mais variados tipos que não são publicados em canais habituais de transmissão científica. Por sua vez, Correia e Borbinha (2001) consideram que a literatura cinzenta abrange uma gama de textos técnicos ou científicos, tais como relatórios de pesquisa, relatórios técnicos, teses, dissertações, documentos governamentais, entre outros tipos.

É interessante notar que a definição de literatura cinzenta sofre variações com o passar do tempo. Segundo Artus (1994), a literatura cinzenta seria disponibilizada - ao menos em uma etapa inicial - a um público científico restrito ou a grupos fechados. Entretanto, com o uso cada vez mais intenso da Internet e com as facilidades de comunicação por ela propiciadas, essa característica tende a ser cada vez menos importante. Sobre isso, Cendón (2002, p.31) apresenta algumas considerações acerca das facilidades propiciadas pelas redes de comunicação: "As novas tecnologias não só permitem maior facilidade de se obterem dados atualizados, como também oferecem ao usuário maior flexibilidade na busca e na manipulação dos dados".

Algumas definições levam em conta aspectos comerciais. Comberousse (1995) define a literatura cinzenta como sendo o conjunto de documentos (relatórios, teses e anais de congressos, por exemplo) que escapam aos circuitos comerciais, representando uma fonte de informações inéditas e com forte valor agregado. De maneira similar, Siegel (2004) comenta que literatura cinzenta é o material que não está disponível em canais de venda, em uma alusão aos livros ou revistas científicas usualmente acessíveis mediante assinatura individual ou de sistemas acadêmicos de busca.

Segundo Correia e Neto (2001), a literatura cinzenta inclui informações tais como relatórios, atas de reuniões técnico-científicas, teses e dissertações, traduções não comercializáveis e documentos oficiais não publicados comercialmente, normas e especificações técnicas, entre outras, disponíveis na forma impressa ou eletrônica.

Carvalho (2001) considera que as divergências de opiniões sobre os documentos que podem ser enquadrados nesse tipo de produção não são tão significativas, avaliando que as definições não diferem muito em sua essência. Desta forma, a literatura cinzenta pode ser entendida como um conjunto de documentos técnicos ou científicos, dos mais variados tipos, tais como relatórios, manuais, apostilas, resumos, sites diversos, entre outros, disponíveis nas mais variadas formas (sejam elas eletrônicas ou impressas), publicados fora dos canais habituais de transmissão científica, 
e que não são submetidos à análise prévia sob a forma de peer-review ou por uma comissão editorial.

Embora sejam constatadas algumas variações entre pesquisadores, entende-se como literatura cinzenta todo texto técnico ou científico não submetido à apreciação ou avaliação sob a forma de peer-review, que garanta a qualidade da metodologia utilizada e dos conceitos emitidos. Adicionalmente, há pesquisadores que incluem a escolha pelos editores ou conselho editorial como um diferencial que permite a separação entre literatura cinzenta ou branca, na medida em que essa seleção garante maior qualidade do texto publicado (CÔRTES, 2004; CORREIA, 2001).

Com a utilização crescente dos meios eletrônicos de armazenamento e difusão, assim como das redes de comunicação, a literatura cinzenta teve o seu uso ampliado. Atualmente, parece correto considerar que uma parte das informações recebidas na academia é obtida a partir de textos incluídos nesse grupo, sendo divulgadas ou disponibilizadas por meio de canais informais diversos. Mesmo com o predomínio dessa característica e, em que pese a ausência de um controle de qualidade usualmente aceito na academia, a literatura cinzenta reveste-se de grande importância, especialmente pela rápida difusão de informações e conhecimentos, e pela sua especial importância como fonte primária.

Conforme mencionado, esse tipo de literatura constitui, não raramente, a única fonte primária disponível sobre determinados assuntos ou temas emergentes. Relatórios produzidos por órgãos governamentais ou entidades do terceiro setor, por exemplo, ao apresentarem levantamentos sobre contextos ou condições sociais e econômicas de regiões ou setores específicos, são potencialmente úteis ao incremento de pesquisas acadêmicas, favorecendo o desenvolvimento de outros estudos e análises. Nesse escopo, Correia e Borbinha (2001) e Almeida (2000) consideram que ela é de grande valor para os pesquisadores porque provê informação que não apareceria em outras fontes, sendo habitualmente mais sucinta e focada, como acontece com os relatórios técnicos.

Sua análise mostra-se importante também no estudo de temas inovadores ou interdisciplinares, conforme manifestado por Correia e Neto (2001):

embora tais relatórios muitas vezes se destinem apenas a informar a entidade patrocinadora acerca do trabalho realizado, são importantes fontes de informação primária que freqüentemente não chega a ser publicada de outra forma, porque, em virtude do caráter interdisciplinar do trabalho, não existem publicações periódicas às quais esses conteúdos possam ser submetidos para publicação, caso os seus autores pretendam divulgar os resultados obtidos (CORREIA; NETO, 2001, p. 4).

Desta forma, apenas os resultados da pesquisa e suas conclusões mais afeitas a uma área específica do conhecimento são divulgados em eventos ou revistas científicas, ficando perdida a informação 
multidisciplinar eventualmente obtida durante o desenvolvimento da pesquisa.

Ao contrário do que ocorre com a chamada literatura branca, em que os critérios de seleção, análise e publicação garantem uma qualidade mínima, a literatura cinzenta apresentaria diferentes gradações, sendo possível encontrar documentos com elevado grau de confiabilidade e importância (por exemplo, resultados de pesquisas de órgãos como IBGE e Receita Federal) e outros que suscitariam dúvidas sobre sua relevância ou consistência (como notas preliminares e pessoais sobre um determinado tema).

Um exemplo dessa situação pode ser verificado no dia-a-dia acadêmico. Embora autores como Correia e Neto (2001) e Comberousse (1995), por exemplo, considerem como literatura cinzenta as dissertações ou teses desenvolvidas em programas regulares de mestrado ou doutorado, parece correto considerar que elas têm um peso acadêmico muito maior do que apostilas, sendo usualmente tomadas como referências válidas.

Tendo em perspectiva essas diferenças e pesos entre documentos considerados como literatura cinzenta, Di Cesare e Sala (1995) desenvolveram uma proposta de gradação, considerando como cinzaclaro, portanto de maior valor, notas e atas de reuniões e encontros, passando pelos relatórios e teses (enquadrados como cinza-médio) e chegando ao cinza-escuro, de menor valor, e que são exemplificados pelas comunicações privadas e materiais não publicados.

Há que se considerar, adicionalmente, a mudança de classificação sofrida por alguns textos, que passam da literatura cinzenta para a branca à medida que são submetidos e aceitos pelos canais convencionais de divulgação científica. Para exemplificar essa situação, têm-se os casos em que um relatório de pesquisa resulta em um artigo publicado por uma revista científica ou quando uma dissertação ou tese passa pelo mesmo processo.

\subsection{Fontes de informação: algumas características e atributos}

À classificação de fontes de informação como literatura branca ou cinzenta (e os tons intermediários), podem ser associados outros parâmetros que compõem uma matriz multidimensional, abrangendo diferentes aspectos. Para que essa análise seja mais abrangente, é necessário verificar não apenas a informação disponibilizada, mas também o sistema que gera ou distribui essa informação. Sendo assim, entende-se que não basta somente analisar a qualidade dos textos publicados por uma revista científica, mas considerar outros aspectos de igual relevância. Para isso, foram considerados quesitos tais como nível de utilização, facilidade de acesso, qualidade, atualidade e veracidade, os quais são detalhados e justificados no decorrer deste tópico. A aplicação desses 
quesitos também foi efetuada em outras fontes de informação estudadas, como sites e bases eletrônicas.

Dentro da perspectiva em que diferentes quesitos são considerados, Arouck (2001), por exemplo, identificou três níveis para a avaliação de sistemas informacionais: a qualidade do sistema (nível técnico); a qualidade da informação (nível semântico); e o uso do sistema (nível de eficácia), que envolve a satisfação do usuário, o impacto individual, impacto no grupo de trabalho ou na organização. Freitas e Kladis (1995) partem da análise dos atributos das informações para, em um segundo momento, avaliar a eficiência dos sistemas. Segundo os autores,...

... as informações fornecidas por um sistema de informação devem atender a alguns atributos para que possam ser significativas no momento da tomada de decisão. Quando esses atributos não são observados, a própria eficiência do sistema começa a ser questionada. (FREITAS; KLADIS, 1995, p. 79).

Eles destacam atributos da informação, como, por exemplo: finalidade, modo e formato, redundância e eficiência, velocidade, freqüência, custo, valor, confiabilidade e precisão, exatidão, validade e atualidade. Esta foi a perspectiva adotada por Côrtes (2008), que também faz ponderações sobre atributos da informação, buscando melhor qualificar seu uso sob diferentes aspectos.

Moresi (2000), por sua vez, apresenta a classificação da informação segundo a sua finalidade quanto à expectativa dos clientes (usuários da informação); proposição adotada por Ribeiro (2005), que ressalta a tendência na avaliação de sistemas informacionais de acordo com a necessidade dos usuários. Dacol, Stollenwerk e Dou (1999) fazem uma retrospectiva do assunto, abordando a análise com ênfase no conteúdo e a avaliação da informação centrada no usuário. Discorrem também sobre abordagens mistas, utilizando novos modelos e novos critérios: a) Modelo de Marchand (com oito dimensões inter-relacionadas); b) Modelo de Olaisen (com quatro categorias de qualidade e valor); c) Modelo de Figueiredo (estudos de usos e usuários da informação); d) Modelo de Lang (estudo de fontes de referência em bibliotecas); e) Modelo de Perel e Young (estudo de fontes para Inteligência Competitiva).

Outros trabalhos mostram aspectos diversos sobre a avaliação de sistemas ou fontes de informação e seus produtos. Zambon et al. (2006), por exemplo, discorrem sobre a fidedignidade de modelos de sistemas, enquanto Xifra-Heras (1975) tece considerações sobre a informação cotidiana. Dias (2002) apresenta um modelo para avaliação de sistemas de informação, enquanto Tarapanoff, Araújo Júnior e Cormier (2000) falam sobre o valor da informação e sua validade em processos decisórios. Nehmy e Paim (1998) discorrem sobre a questão da qualidade da informação.

Considerando os quesitos utilizados na pesquisa para a qualificação das publicações analisadas, o primeiro deles (nível de utilização) revela a 
efetividade dos estímulos recebidos pelos usuários, sendo um reflexo da qualidade do sistema que provê as informações (DIAS, 2002). Arouck (2001) pondera que este é um dos quesitos usualmente utilizados para qualificar os sistemas informacionais. Adicionalmente, Côrtes (2008) observa que, sendo um atributo que indica a quantidade de vezes que uma informação é empregada, o nível de utilização possibilita prospectar as necessidades dos usuários em relação a um determinado tipo ou serviço de informação.

Em relação aos jornais, periódicos não científicos e sites comerciais, uma característica que tem especial relevância é a facilidade de acesso, sendo um predicado que repercute na competitividade da publicação. Para Tarapanoff, Araújo Júnior e Cormier (2000), a postura competitiva associa-se à proatividade em atender às demandas dos usuários, estando intimamente relacionada à antecipação de tendências, à melhor oferta de produtos e serviços e também à facilidade de acesso.

A qualidade constitui um constructo elaborado pela combinação de impressões diversas, sendo o mais abrangente dos quesitos adotados. Dias (2002) observa que o "princípio da qualidade" está associado aos fatores que determinam o grau de satisfação do usuário final, o que reforça a idéia de um amplo constructo. Sobre isso, Paim, Nehmy e Guimarães (1996) consideram que, embora ela possa ser entendida como uma matriz multidimensional, não há consenso na literatura sobre definições teóricas e operacionais da qualidade da informação. Apesar disso, segundo esses autores, há uma tendência em estudar a qualidade sob três vertentes: valor transcendente, aspectos intrínsecos e atributos contingenciais. Arouck (2001), a partir de uma ampla revisão bibliográfica, reforça o uso de uma matriz multidimensional para a análise da qualidade da informação.

Segundo Xifra-Heras (1975), um grande número de critérios pode ser adotado para estabelecer uma tipologia do fenômeno informativo. Segundo ele, a informação não se define pelo seu objetivo, mas pelo seu fim, possibilitando uma série de classificações. Uma delas é a informação cotidiana, que se divulga mediante os meios de comunicação de massa (como a imprensa). Embora Xifra-Heras (1975) reconheça a falta de precisão dessa denominação, ela tem a vantagem de que o adjetivo cotidiano pressupõe duas características essenciais desse tipo de informação: a atualidade e a periodicidade. Prosseguindo, Xifra-Heras (1975) considera que a atualidade é essencial para a informação cotidiana (aquela divulgada pelos meios de comunicação). Segundo o autor, a atualidade verifica-se não apenas em novos fatos (relacionados ao momento atual). Ela pode verificar-se em fatos passados divulgados pela primeira vez ou que se apresentam atuais em razão de novos acontecimentos. A mesma opinião é manifestada por Côrtes (2008, p. 29): "mesmo uma informação gerada há algum tempo pode ser atual à medida que fornece subsídios ao entendimento de certos contextos ou situações (ou seja, ela é condizente com o momento presente)". 
Quanto à veracidade, ela representa a capacidade de a publicação ser verdadeira ou representar a verdade. Entretanto, este é um atributo nem sempre lembrado pelos autores. Em pesquisa realizada por Arouck (2001), prospectando artigos referentes à qualidade da informação, a veracidade é mencionada em apenas dois trabalhos de um total de quatorze analisados. Apesar da aparente pequena relevância dada a esse atributo, ele foi utilizado na pesquisa como uma forma de identificar, nos entrevistados, o grau de credibilidade das publicações analisadas.

\section{Considerações sobre a metodologia utilizada}

Em busca de melhor compreensão dos aspectos relacionados ao uso de fontes de documentos não convencionais pelos alunos de graduação em Administração, Ciências Contábeis e Economia, a pesquisa foi dividida em três fases: a) revisão da literatura; b) coleta e tratamento de dados e c) interpretação dos resultados.

Devido ao caráter prospectivo desta pesquisa, no qual a quantificação das diferentes características das publicações ou fontes de referência foi prevista e a análise dos dados obtidos foi efetuada de acordo com um projeto previamente estabelecido, o estudo decorrente assume um caráter exploratório. Como tal, busca aumentar a compreensão de um fenômeno ainda pouco conhecido. Consequentemente, algumas delimitações foram adotadas (garantindo maior rigor metodológico) e outras são previamente conhecidas (sendo inerentes ao método empregado), conforme detalhado a seguir nos tópicos referentes à coleta e tratamento de dados, e à interpretação dos resultados.

\subsection{Coleta de dados}

Para melhor explicar o trabalho de coleta de dados, este tópico foi subdivido em três itens (População e Amostra, Fontes de Referência Selecionadas e Instrumento de Pesquisa), conforme detalhado a seguir.

\subsubsection{População e amostra}

O levantamento foi efetuado com alunos do último ano de graduação dos cursos de Administração, Ciências Contábeis e Economia, de uma instituição particular de ensino superior localizada na cidade de São Paulo (constituindo a população analisada), que opinaram sobre nove atributos que qualificam fontes de referência previamente selecionadas e seus respectivos produtos (textos e informações disponibilizadas).

Foram entrevistados 145 estudantes, compondo uma amostra que pode ser considerada casual (BISQUEIRA ALZINA; CASTELLÁ SARRIERA; MARTÍNEZ, 2004) ou por conveniência (APPOLINÁRIO, 2004), o que a caracteriza como não probabilística. Estimativas e levantamentos da instituição de origem desses estudantes indicam que o índice de ocupação dos alunos do último ano de graduação supera os $90 \%$ e a grande maioria 
trabalha diretamente em atividades relacionadas aos seus cursos ou exerce cargos administrativos em um senso mais amplo.

O survey foi subsidiado por pesquisa bibliográfica (COOPER; SCHINDLER, 2003) e de campo (BABBIE, 2003; MALHOTRA et al., 2005), e a interpretação dos resultados foi realizada com auxílio da estatística descritiva (DANCEY; REIDY, 2006; BISQUERRA ALZINA; CASTELLÁ SARRIERA; MARTÍNEZ, 2004; COSTA NETO, 2002; CARVER; NASH, 2000; FONSECA; MARTINS, 1996; MORETTIN; BUSSAB, 1981). Buscando subsídios para uma comparação dos resultados obtidos, especialmente no que se refere à utilização da literatura cinzenta, foi investigado, adicionalmente, o uso de literatura branca, conforme detalhado a seguir, em Fontes de referência selecionadas.

\subsubsection{Fontes de referência selecionadas}

A vivência em sala de aula indica que os alunos buscam informações não apenas nos livros indicados ou nos artigos científicos sugeridos como leitura complementar pelos professores. É necessário considerar que os estudantes, diante da facilidade e oferta de meios de comunicação, utilizam fontes alternativas àquelas usualmente referenciadas pelos docentes. Para a população analisada, essa busca por informações ocorre não apenas por razões acadêmicas, mas também pela necessidade profissional de se manterem atualizados.

Sobre isso é interessante verificar a pesquisa de Ghisi, Famá e Pimenta Júnior (2001) sobre estratégias didáticas para o ensino de economia e finanças. Os autores destacam as fontes de informação que os estudantes pesquisados utilizam para obter conhecimento: jornais $(39,7 \%)$, sala de aula $(12,7 \%)$, revistas $(11,11 \%)$ e Internet $(9,5 \%)$. Cendón (2002) reforça o uso de bases de dados e serviços de informação de natureza comercial pelos administradores no acompanhamento da concorrência, identificação de ameaças, prospecção de oportunidades e aumento da competitividade.

As fontes selecionadas para esta pesquisa foram publicações classificadas como literatura cinzenta e fontes jornalísticas especializadas que atendem a pelo menos três dos seguintes requisitos: notoriedade, facilidade de acesso, qualidade, atualidade e veracidade. Adicionalmente, foi incluído um grupo que reúne revistas científicas e trabalhos apresentados em congressos, tendo como finalidade estabelecer uma comparação entre o uso de documentos que podem ser classificados como literatura branca e aqueles pertencentes aos grupos mencionados:

Jornais de grande circulação - foram considerados jornais que apresentam cadernos ou suplementos especiais para a área de economia e negócios ou que sejam exclusivamente dedicados a essas áreas. A pesquisa analisou os jornais O Estado de S.Paulo (Caderno de Economia), Folha de S. Paulo (suplemento Dinheiro), Gazeta Mercantil e Valor Econômico. 
Revistas de grande circulação - publicações dirigidas ao público interessado em negócios e que apresentam matérias voltadas para as áreas de finanças, marketing, gestão de carreiras, gestão de pessoal. Foram escolhidas a Revista Exame e Você S.A.

Informações geradas por órgãos governamentais e organização não governamental - informações disponibilizadas pelo IBGE, Receita Federal, Banco Central e DIEESE.

Provedores privados de informação - empresas que, mediante pagamento, fornecem serviços de informação sobre legislação, normas e procedimentos legais, jurisprudência, finanças, contabilidade, entre outros. Na pesquisa, esse grupo é constituído pelo IOB - Thomson e Mapa Fiscal.

Literatura científica - grupo formado por revistas científicas e trabalhos apresentados em congressos (aqui classificados como literatura branca).

Os termos mencionados como qualificativos para a escolha de publicações ou fontes de informação, embora tenham caráter subjetivo, permitem selecionar publicações que possuam atributo ou condição capaz de distingui-las de outras, determinando sua escolha.

É sempre importante lembrar que percepções sobre qualidade, atualidade e veracidade - melhor qualificar as fontes pesquisadas - são subjetivas, e constituem um constructo resultante da percepção, pensamento e combinação de impressões passadas e presentes.

\subsubsection{Instrumento de pesquisa}

O instrumento de pesquisa constitui-se em um questionário (QUADRO I), em que, para cada fonte de informação previamente selecionada, os entrevistados puderam manifestar sua opinião por meio da aplicação de uma escala Likert com seis posições ( $\left.\begin{array}{lll}0 & \text { a } & 5\end{array}\right)$. Adicionalmente, os quesitos utilizados foram explicados na parte inferior do questionário, procurando evitar dúvidas por parte dos entrevistados. 0 instrumento de pesquisa foi originalmente testado e validado em um grupo de alunos que não participaram da pesquisa final. Com isso, foi possível aprimorar o questionário, tanto em sua forma quanto em seu conteúdo, facilitando sua utilização final (COOPER; SCHINDLER, 2003; HILL; HILL, 2002; MALHOTRA et al., 2005).

As respostas foram tabuladas e processadas com a utilização do software SPSS (Statistical Package for the Social Sciences), visando à obtenção de parâmetros estatísticos descritivos, facilitando a análise e a interpretação das opiniões coletadas. Para isso, buscou-se apoio em bibliografia especializada para melhor uso do software adotado e para a correta interpretação dos resultados (DANCEY; REIDY, 2006; BISQUERRA ALZINA; CASTELLÁ SARRIERA; MARTÍNEZ, 2004; COSTA NETO, 2002; 
CARVER; NASH, 2000; PESTANA; GAGEIRO, 2000; FONSECA; MARTINS, 1996; MORETTIN; BUSSAB, 1981).

QUADRO I - Questionário aplicado

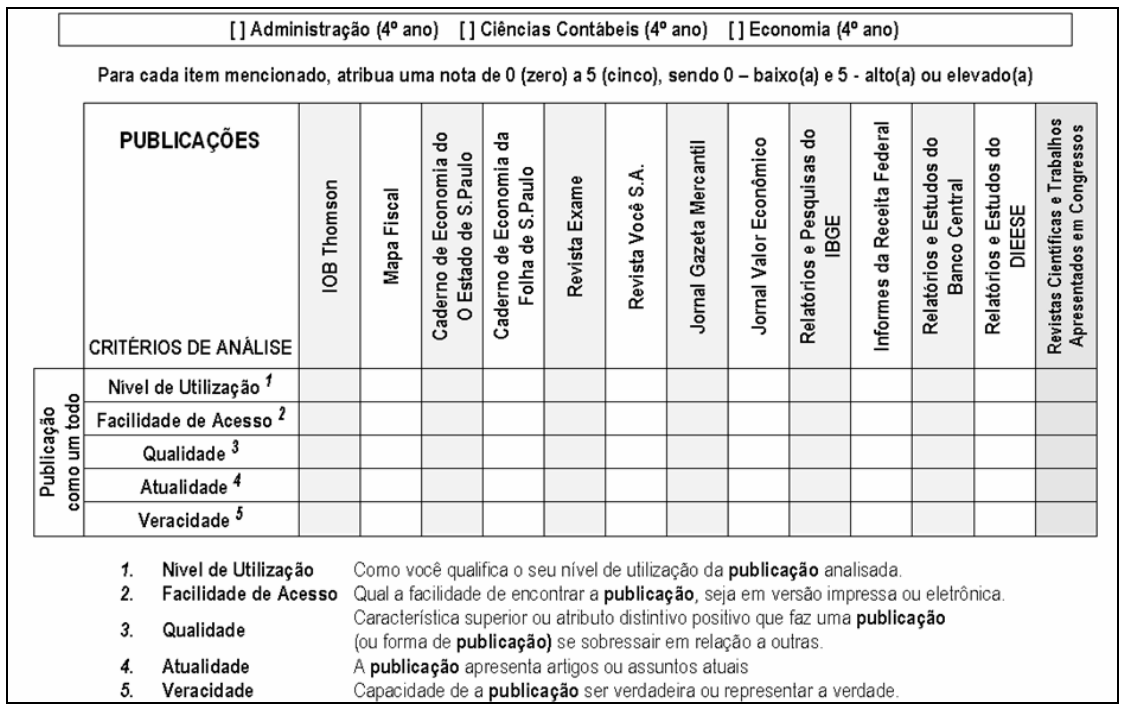

Fonte: Dados da pesquisa.

\section{Resultados da pesquisa}

A seguir, são apresentados os resultados e as respectivas interpretações para cada grupo, abrangendo fontes de informação classificadas como literatura cinzenta. Foi efetuada a comparação com os resultados obtidos para o grupo literatura científica, utilizada como parâmetro comparativo.

\subsection{Literatura científica}

Integram esse grupo revistas científicas e trabalhos apresentados em congressos, em um sentido mais amplo, buscando qualificar o uso de literatura branca pelos alunos. Objetivou-se estabelecer um parâmetro que permitisse verificar o hábito de consultar publicações científicas comparativamente às publicações consideradas como literatura cinzenta ou de caráter jornalístico (ou ainda de divulgação).

Identificou-se que, apesar de os entrevistados serem alunos do último ano de graduação, o nível de utilização da literatura científica é baixo (média $=2,02$, desvio padrão $=1,84$ ). É interessante notar que os entrevistados indicaram certa dificuldade de acesso (média $=2,39$, desvio padrão $=1,73$ ), mas isso não corresponde à realidade da instituição de origem desses estudantes, pois ela possui uma boa biblioteca, com amplo acervo e facilidade de acesso a textos acadêmicos, incluindo a base de dados Business Source Premier (EBSCO). Talvez essa "dificuldade de acesso" seja mais um reflexo de um hábito pouco desenvolvido de 
pesquisar textos e trabalhos científicos, ensejando perspectivas para estudos posteriores.

Apesar do baixo nível de utilização, a qualidade (média $=2,84$; desvio padrão $=1,69$ ), a atualidade ( édia $=2,84$; desvio padrão $=$ 1,68 ) e a veracidade (média $=2,92$; desvio padrão $=1,64$ ) ficaram acima do ponto central da escala utilizada (0 a 5), conforme pode ser visto na TAB. 1 e na FIG. 1. Quando levado em consideração o nível de utilização, esse resultado pode ser um indicativo de que esses quesitos foram possivelmente avaliados mais com base em percepções colhidas de professores do que como resultado do uso efetivo.

TABELA 1- Resultados do Grupo Literatura Científica

\begin{tabular}{|c|c|c|c|}
\hline & & & Literatura Científica \\
\hline \multirow{10}{*}{ 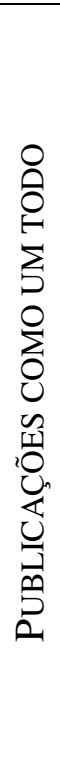 } & \multirow{2}{*}{ Nível de Utilização } & Média & 2,02 \\
\hline & & $\mathrm{DP}$ & 1,84 \\
\hline & \multirow{2}{*}{ Facilidade de Acesso } & Média & 2,39 \\
\hline & & $\mathrm{DP}$ & 1,73 \\
\hline & \multirow{2}{*}{ Qualidade } & Média & 2,84 \\
\hline & & $\mathrm{DP}$ & 1,69 \\
\hline & \multirow{2}{*}{ Atualidade } & Média & 2,84 \\
\hline & & DP & 1,68 \\
\hline & \multirow{2}{*}{ Veracidade } & Média & 2,92 \\
\hline & & DP & 1,64 \\
\hline
\end{tabular}

Fonte: Dados da pesquisa.

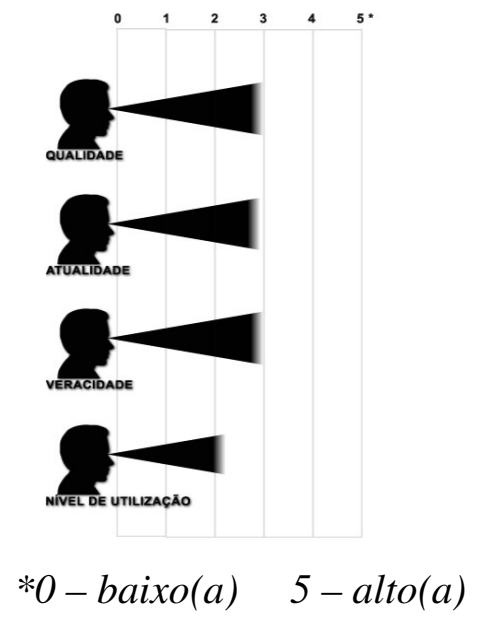

FIGURA 1 - Literatura Científica: Síntese dos Resultados Obtidos

Fonte: Dados da pesquisa. 


\subsection{Jornais de grande circulação}

Integram esse grupo os jornais O Estado de S. Paulo (caderno de Economia), Folha de S. Paulo (suplemento Dinheiro), Gazeta Mercantil e Valor Econômico. O nível de utilização apresentou média igual a 2,4 (desvio padrão de 1,79), mostrando um uso razoável das fontes de informação pertencentes a esse grupo. Em função disso, a qualidade ( édia $=3,3$; desvio padrão $=1,56$ ), atualidade (média $=3,6$; desvio padrão $=1,62$ ) e veracidade (média $=3,3$; desvio padrão $=1,55$ ) puderam ser avaliadas com maior adequação, conforme apresentado na TAB. 2 e na FIG. 2.

O grupo entrevistado mostrou uso um pouco mais intenso de jornais (média $=2,4$ ), em comparação à literatura científica (média $=2,02$ ). É possível que esse uso tenha levado a uma melhor avaliação do grupo representado pelos Jornais de Grande Circulação nos demais quesitos (Tabela 2).

Verificou-se que, para a população pesquisada, os cadernos ou suplementos de economia e negócios e os jornais especializados nesse segmento representam fonte de referência e informação. Os três quesitos (qualidade, atualidade e veracidade) contribuem de maneira praticamente igual para a boa avaliação desse grupo, com destaque para a atualidade (um pouco melhor avaliada).

A dinâmica dessas publicações, com edições diárias e informações atuais, o baixo custo e a facilidade de acesso constituem ingredientes importantes que incentivam 0 uso habitual dessas fontes. Essa característica pode ser aplicada favoravelmente para fins didáticos, uma vez que textos jornalísticos selecionados podem ser utilizados para fomentar discussões e auxiliar na aplicação prática de conceitos e teorias.

TABELA 2 - Comparativo entre Jornais de Grande Circulação e Revistas de Grande Circulação

\begin{tabular}{|c|c|c|c|c|c|}
\hline & & & $\begin{array}{c}\text { Jornais de } \\
\text { Grande } \\
\text { Circulação }\end{array}$ & $\begin{array}{c}\text { Revistas de } \\
\text { Grande } \\
\text { Circulação }\end{array}$ & $\begin{array}{l}\text { Literatura } \\
\text { Científica }\end{array}$ \\
\hline \multirow{10}{*}{ 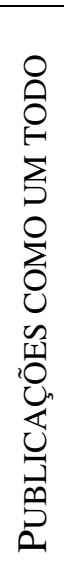 } & \multirow{2}{*}{ Nível de Utilização } & Média & 2,41 & 2,47 & 2,02 \\
\hline & & $\mathrm{DP}$ & 1,79 & 1,75 & 1,84 \\
\hline & \multirow{2}{*}{ Facilidade de Acesso } & Média & 3,18 & 3,08 & 2,39 \\
\hline & & DP & 1,79 & 1,79 & 1,73 \\
\hline & \multirow{2}{*}{ Qualidade } & 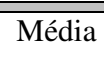 & $\overline{3,27}$ & 3,20 & 2,84 \\
\hline & & $\mathrm{DP}$ & 1,56 & 1,53 & 1,69 \\
\hline & \multirow{2}{*}{ Atualidade } & 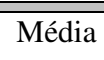 & 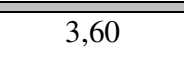 & 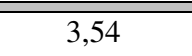 & 2,84 \\
\hline & & $\overline{\mathrm{DP}}$ & 1,62 & 1,53 & 1,68 \\
\hline & \multirow{2}{*}{ Veracidade } & Média & 3,27 & 3,11 & 2,92 \\
\hline & & $\mathrm{DP}$ & 1,55 & 1,55 & 1,64 \\
\hline
\end{tabular}

Fonte: Dados da pesquisa 


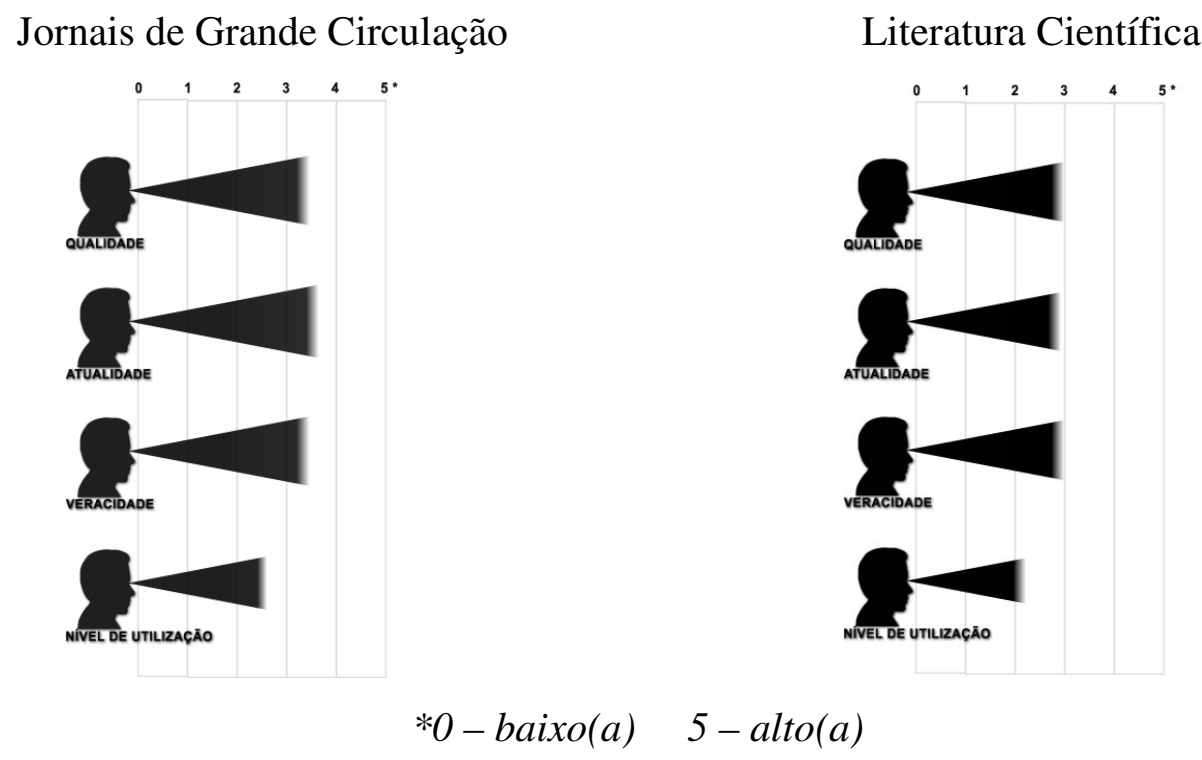

FIGURA 2 - Jornais de Grande Circulação: Síntese dos Resultados e Comparativo com a Literatura Científica

Fonte: Dados da pesquisa.

O uso de documentos não convencionais pode constituir-se em uma estratégia de ensino, desde que amparado por critérios definidos pelos professores, atraindo o interesse do aluno de graduação para temas considerados mais áridos. Conforme os resultados da pesquisa indicam, há uma preferência dos alunos por esse tipo de texto comparativamente à literatura científica.

Sobre isso, é interessante verificar algumas considerações encontradas na literatura. Anderson e Baldwin (2003), por exemplo, propõem uma estratégia de pesquisa, desenvolvida com alunos de graduação, em que a literatura cinzenta (relatórios técnicos, websites, eprints e preprints, por exemplo) seja utilizada para que um entendimento inicial do tema pesquisado seja estabelecido. Posteriormente, os estudantes utilizariam a literatura branca, ampliando e aprofundando o tema pesquisado.

Uma evidência que aponta para a eficácia de técnicas de ensino baseadas na leitura de textos adicionais pode ser verificada em Camargos, Camargos e Machado (2006). Em pesquisa sobre as preferências de ensino, desenvolvida com graduandos em Administração, os autores verificaram, por exemplo, que "os alunos têm preferência pelos professores que incentivam a leitura $(63,4 \%)$, o uso da biblioteca $(80,3 \%)$ e a busca por outros livros/textos, além dos que estão indicados na bibliografia do curso $(77 \%)$ " (CAMARGOS, CAMARGOS e MACHADO, 2006, p.10). 


\subsubsection{Revistas de grande circulação}

Constituído pelas Revistas Exame e Você S.A., este grupo apresentou resultados similares aos obtidos pelo grupo "Jornais de Grande Circulação", conforme pode ser verificado na Tabela 2. A média para o quesito nível de utilização foi de 2,47 (desvio padrão $=1,75$ ). Os quesitos qualidade (média $=3,2$; desvio padrão $=1,53$ ), atualidade (média $=3,5$; desvio padrão $=1,53$ ) e veracidade (média $=3,1$; desvio padrão $=1,55$ ) também foram bem avaliados, com um leve destaque para a atualidade (FIG. 3), mantendo a semelhança com o grupo formado pelos Jornais de Grande Circulação.

Similarmente ao que ocorre com os jornais (ou cadernos de jornais) especializados na área de economia e negócios, os estudantes entrevistados têm no grupo das Revistas de Grande Circulação uma fonte razoável de referência e informação. Em relação à literatura científica, o grupo analisado mostrou um uso levemente mais intenso (média de 2,5 para as revistas contra uma média de 2,02 para a literatura científica).

A atualidade é um quesito bem avaliado pela população analisada, sendo um dos motivos que contribuem para a aceitação dessas publicações (juntamente com a qualidade e a veracidade). Embora o trabalho jornalístico não apresente o rigor metodológico necessário aos textos acadêmicos, ele pode ser potencialmente útil na análise preliminar de casos, ajudando no entendimento de contextos políticos e econômicos.

Jornais de Grande Circulação

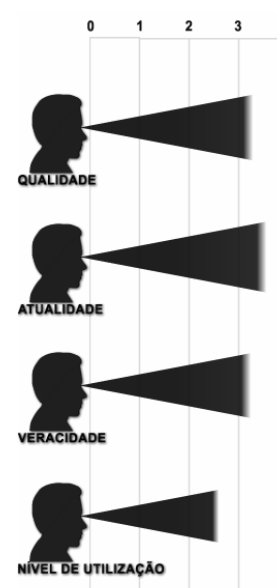

Literatura Científica

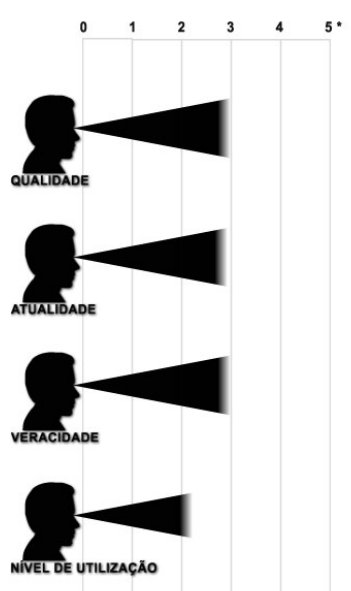

$$
* 0-\text { baixo(a) } \quad 5-\operatorname{alto}(a)
$$

FIGURA 3 - Revistas de Grande Circulação: Síntese dos Resultados e Comparativo com a Literatura Científica Fonte: Dados da pesquisa.

Sobre isso, é oportuno mencionar Rezende (2002, p.122): "A formulação estratégica de qualquer negócio sempre é feita a partir das informações disponíveis e, portanto, nenhuma estratégia consegue ser melhor que a informação da qual é derivada". Prosseguindo, a autora comenta que a inteligência competitiva consiste no monitoramento do ambiente concorrencial e não apenas no ambiente mercadológico, afirmando que "será a habilidade com que a empresa coleta, organiza, analisa e implementa mudanças a partir de informações, integrando-as ao 
processo de melhoria contínua de suas atividades, que irá determinar a sua excelência" (REZENDE, 2002, p.122).

Dentro desse escopo, as informações jornalísticas bem qualificadas podem constituir-se em material de referência para os gestores de empresas e negócios. É importante reforçar a importância do docente ao ajudar os alunos na seleção e bom uso dessas fontes, por apresentarem informações atualizadas sobre empresas, novas legislações ou normas.

Acredita-se que, quando bem selecionados, artigos de revistas possam constituir material potencialmente útil para aulas, ajudando a dinamizar discussões e criando cenários úteis à aplicação de teorias científicas. Além disso, o texto jornalístico de boa procedência tem o mérito de incentivar a leitura, criando um hábito que ajuda na formação de pessoas mais críticas.

\subsubsection{Informações geradas por Órgãos Governamentais e ONG}

Embora sejam considerados literatura cinzenta, os estudos, informes e relatórios publicados pelo IBGE, Receita Federal, Banco Central e DIEESE têm sua relevância comparável aos artigos publicados em revistas científicas.

Devido à natureza do trabalho que desenvolvem, organizações como IBGE e DIEESE possuem grandes quantidades de dados primários, estabelecendo-se em fonte primordial para a realização de diversos estudos. Por outro lado, órgãos como a Receita Federal e o Banco Central, além de terem dados relacionados à natureza de suas atribuições (que podem subsidiar a realização de estudos e análises), têm em seus informes um caráter normativo, regulatório ou interpretativo da legislação vigente.

Verificou-se que o nível de utilização é baixo (média $=1,5$, desvio padrão $=1,75)$, repercutindo na avaliação da qualidade, atualidade e veracidade. Verifica-se que o desvio padrão calculado é superior à média, comprometendo o resultado obtido (TAB. 3).

Mesmo assim, as médias verificadas (qualidade $=2,4$; atualidade $=$ 2,5 ; veracidade $=2,6$ ) permitem concluir que as pessoas que não utilizam essas fontes de informação têm uma percepção razoável delas, embora seja necessário ressalvar que os respectivos desvios padrão são elevados (qualidade $=1,83$; atualidade $=1,87$; veracidade $=1,89$ ).

Dos grupos analisados, é um dos que têm um dos menores níveis de utilização, apresentando resultado um pouco inferior ao grupo "Literatura Científica" (médias 1,5 e 2,02 respectivamente). Em ambos os casos, 0 desvio padrão é elevado.

Isso leva a crer que existe um potencial de uso a ser explorado dos estudantes entrevistados. Embora o trabalho não tenha analisado questões relativas às interfaces de utilização e, portanto, não ofereça subsídios para a afirmação que se segue, supõe-se que um dos empecilhos à utilização dessas fontes seja a dificuldade de encontrar a 
informação desejada nos respectivos sites na Internet. Outra razão que pode ser suposta é a falta de conhecimento mais amplo quanto aos conteúdos disponíveis.

TABELA 3 - Comparativo entre Órgãos Governamentais / ONG e Provedores Privados de Informação

\begin{tabular}{|c|c|c|c|c|c|}
\hline & & & $\begin{array}{c}\text { Órgãos } \\
\text { Governamenta } \\
\text { is e ONG }\end{array}$ & $\begin{array}{l}\text { Provedores } \\
\text { Privados de } \\
\text { Informação }\end{array}$ & $\begin{array}{l}\text { Literatura } \\
\text { Científica }\end{array}$ \\
\hline \multirow{10}{*}{ 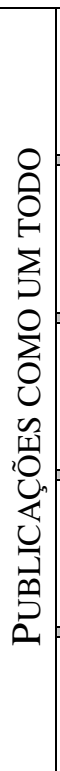 } & \multirow{2}{*}{ Nível de Utilização } & Média & 1,48 & 1,02 & 2,02 \\
\hline & & DP & 1,75 & 1,62 & 1,84 \\
\hline & \multirow{2}{*}{ Facilidade de Acesso } & Média & $\overline{~ 1,96}$ & 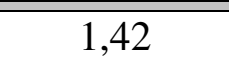 & 2,39 \\
\hline & & $\mathrm{DP}$ & 1,83 & 1,78 & 1,73 \\
\hline & \multirow{2}{*}{ Qualidade } & Média & 2,44 & 1,98 & 2,84 \\
\hline & & DP & 1,83 & 1,88 & 1,69 \\
\hline & \multirow{2}{*}{ Atualidade } & Média & 2,45 & 2,20 & 2,84 \\
\hline & & $\mathrm{DP}$ & 1,87 & 2,08 & 1,68 \\
\hline & \multirow{2}{*}{ Veracidade } & Média & 2,56 & 2,25 & 2,92 \\
\hline & & $\mathrm{DP}$ & 1,89 & 2,04 & 1,64 \\
\hline
\end{tabular}

Fonte: Dados da pesquisa.

Sobre o uso dessas fontes em estratégias de ensino, é oportuno verificar o trabalho de Miranda e Miranda (2006). Discutindo a interdisciplinaridade e os métodos de ensino de contabilidade, os autores discorrem sobre a aplicação de conhecimentos obtidos após a discussão de casos e o desenvolvimento, por parte dos alunos, de resumos de leituras. Segundo eles, essas estratégias facilitariam o desenvolvimento da capacidade de utilização de informações, gerando e permitindo o teste de novas idéias, levando a um aprimoramento pessoal dos alunos e a uma melhor gestão de seu próprio aprendizado. Uma possibilidade, por exemplo, é a utilização de textos disponíveis em sites oficiais (com normas regulatórias e orientações sobre a legislação) para o desenvolvimento de estudos específicos.

Oliveira (2004) mostra que, dentre as fontes de informação mais utilizadas por executivos, incluem-se as publicações governamentais, o que indica a importância do seu uso por parte dos alunos. Uma sugestão que pode ampliar o uso dessas fontes de informação é utilizar em aula os dados oriundos dessas fontes primárias, permitindo a elaboração de análises que expliquem determinados contextos socioeconômicos necessários à formulação de planos de negócio e estratégia de marketing, por exemplo. 
Informações Geradas por Órgãos Governamentais e

Organização Não-Governamental

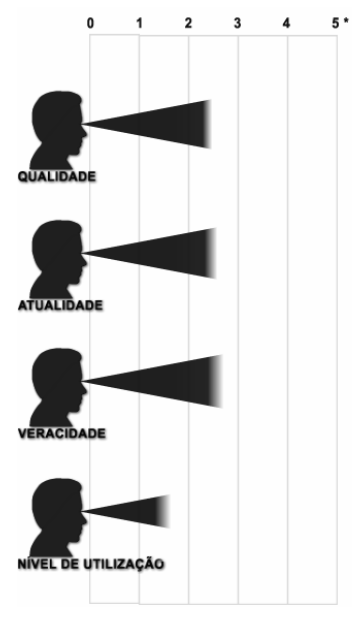

Literatura Científica

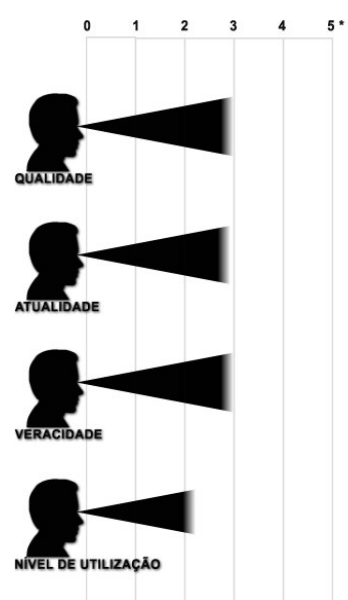

$$
* 0-\operatorname{baixo}(a) \quad 5-\operatorname{alto}(a)
$$

FIGURA 4 - Informações Geradas por Órgãos Governamentais e ONG: Síntese dos Resultados e Comparativo com a Literatura Científica

Fonte: Dados da pesquisa.

\subsection{Provedores privados de informação}

Esse grupo é composto por empresas que fornecem serviços de informação sobre legislação, normas e procedimentos legais, jurisprudência, finanças, contabilidade, entre outros, mediante pagamento de assinaturas, sendo representado na pesquisa pelo IOB - Thomson e Mapa Fiscal. A TAB. 3 mostra conjuntamente os resultados para os grupos "Órgãos Governamentais e ONG" e "Provedores Privados de Informação", possibilitando uma comparação direta entre eles.

Provedores Privados de Informação

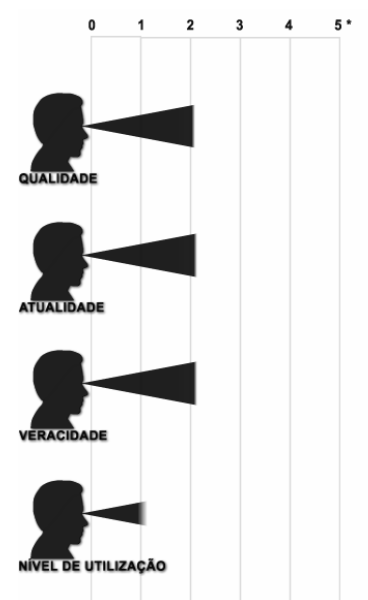

Literatura Científica

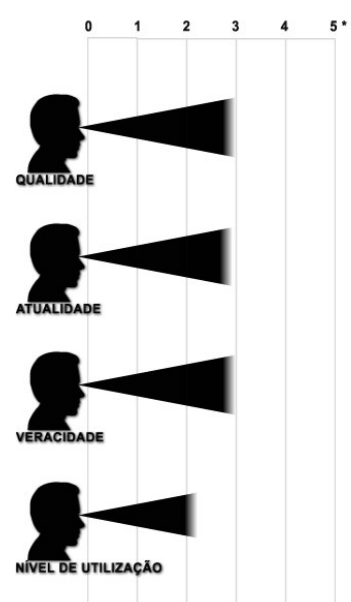

$* 0$ - baixo(a) $5-\operatorname{alto}(a)$ 
FIGURA 5 - Provedores Privados de Informação: Síntese dos Resultados e Comparativo com a Literatura Científica

Fonte: Dados da pesquisa.

Verificou-se que, em função do baixo nível de utilização (média de 1,02 para o grupo, com desvio padrão de 1,62), esse grupo teve sua qualidade (média $=2,0$; desvio padrão $=1,88$ ), atualidade (média $=2,2$; desvio padrão $=2,08$ ) e veracidade (média $=2,2$; desvio padrão $=2,04$ ) mal avaliadas, como indica a FIG. 5. Os desvios padrão obtidos foram elevados, comprometendo a análise das médias. De qualquer forma, o baixo nível de utilização mostra que, para os estudantes de graduação entrevistados, os Provedores Privados de Informação não constituem fonte primordial de informação ou referência. A média obtida para o nível de utilização foi praticamente a metade daquela calculada para a literatura científica, revelando o baixíssimo uso dessas fontes.

\section{Conclusões}

O estudo empreendido constatou que as fontes de informação usuais para os alunos entrevistados são aquelas que integram os grupos "Jornais de Grande Circulação" e "Revistas de Grande Circulação", o que é indicado pelo nível de utilização observado. O grupo "Informações Geradas por Órgãos Governamentais e Organização Não Governamental", congregando o IBGE, Banco Central, Receita Federal e DIEESE, não constitui fonte importante de informações para os alunos entrevistados, ficando à frente apenas dos "Provedores Privados de Informação" (que cobram pelos serviços prestados).

Mesmo considerando os três grupos mais utilizados (jornais, revistas e literatura científica), verifica-se que o nível de utilização é no máximo razoável, evidenciando uma falta de "apetite para a leitura" entre os alunos entrevistados. Além disso, uma análise dos resultados permite inferir que os entrevistados têm uma preferência pela informação já trabalhada ou processada e interpretada (informações jornalísticas), uma vez que fontes potenciais de dados primários são muito pouco utilizadas.

Embora os alunos tenham relatado uma baixa facilidade de acesso às diversas fontes de informações analisadas, isso pode ser mais um sintoma da falta de hábito de leitura do que uma dificuldade em acessar determinadas fontes. Jornais e revistas de grande circulação amplamente disponíveis (inclusive na biblioteca da instituição de origem desses estudantes) obtiveram média pouco superior a três no quesito facilidade de acesso.

É possível que a baixa utilização das fontes do grupo "Informações Geradas por Órgãos Governamentais e Organização Não Governamental" também seja explicada pela dificuldade em localizar as informações desejadas em meio a interfaces nem sempre amigáveis e pela própria falta de hábito dos entrevistados, embora essa explicação não possa ser confirmada pela pesquisa realizada. 
Não obstante o fato de algumas fontes de informação serem pouco utilizadas, a percepção geral dos entrevistados tende a ser boa (mesmo entre os não usuários), indicando a existência de uso potencial ainda não explorado (ou a ser efetivado). Acredita-se que a participação dos docentes como catalisadores dessa reação, em prol do aumento do número de leitores e usuários de informações qualificadas, seja de fundamental importância.

Levando em conta algumas características inicialmente consideradas negativas, tais como a ausência de peer-review, a baixa perenidade e a ausência de controle bibliográfico, o uso da literatura cinzenta deve ser considerado uma opção válida, especialmente como fonte primária de dados e informações, a partir de relatórios e informes publicados em sites oficiais, por exemplo. É necessário, todavia, que esse uso seja orientado e supervisionado pelos docentes.

A pesquisa realizada demonstra que a leitura é um hábito pouco difundido entre os estudantes, independente de a fonte ser on-line ou impressa. Esta é uma situação percebida pelos docentes em seu dia-a-dia em sala de aula, refletindo-se não somente na qualidade dos textos e trabalhos produzidos pelos alunos, mas também na fundamentação da informação assimilada.

$\mathrm{O}$ instrumento de pesquisa mostrou-se adequado ao entendimento inicial de um cenário bastante complexo, abrindo espaço para seu aprimoramento futuro. Avalia-se que essa pesquisa possa ser replicada em outras instituições de ensino, abrangendo também alunos de pósgraduação lato sensu, atraindo novos pesquisadores e ampliando os resultados obtidos.

\section{Referências}

ALMEIDA, M. R. G. Literatura cinzenta: teoria e prática. São Luís: UFMA, 2000.

ANDERSON, M.; BALDWIN, V. Are they really teachers? Problem-based learning and information professionals. To Improve the Academy: Resources for Faculty, Instructional, and Organizational Development, Bolton, MA, v. 21, p. 273-287. 2003.

APPOLINÁRIO, F. Dicionário de metodologia científica: um guia para a produção do conhecimento científico. São Paulo: Atlas, 2004.

AROUCK, O. Avaliação de Sistemas de Informação: Revisão da Literatura. Transinformação, Campinas, SP, v. 13, n. 1, p. 7-21, janeiro/junho 2001.

ARTUS, H. M. A. Grey literature and the author / respondant relantionship. In: INTERNATIONAL CONFERENCE ON GREY LITERATURE, 1., 1993. Proceedings... Amsterdã: TransAtlantic, 1994. p. 290-307.

BABBIE, E. Métodos de pesquisa de survey. Belo Horizonte: Editora UFMG, 2003. 
BISQUERRA ALZINA, R.; CASTELLÁ SARRIERA, J.; MARTÍNEZ, F. Introdução à estatística: enfoque informático com o pacote estatístico SPSS. Porto Alegre: Artmed, 2004.

CAMARGOS, M. A.; CAMARGOS, M. C. S.; MACHADO, C. J. Análise das Preferências de Ensino de Alunos de um Curso Superior de Administração de Minas Gerais. Revista de Gestão USP, São Paulo, SP, v. 13, n. 2, p. 114, abril/junho. 2006.2 Disponível em: <http://www.regeusp.com.br/arquivos/431.pdf>. Acesso em: 25 nov. 2009.

CARVALHO, E. M. R. La literatura gris y su contribución a la sociedad del conocimiento. In.: IFLA COUNCIL AND GENERAL CONFERENCE, 67., 2001, Boston. Libraries and librarians: making a difference in the knowledge age. Boston, 2001. Disponível em: $<$ http://archive.ifla.org/IV/ifla67/papers/090-173s.pdf>. Acesso em: 25 nov. 2009.

CARVER, R. H.; NASH, J. G. Doing data analysis with SPSS 10.0. Pacific Grove: Duxbury Press, 2000.

CENDÓN, B. V. Bases de dados de informação para negócios. Ciência da Informação, Brasília, DF, v. 31, n. 2, p. 30-43, mai/ago. 2002. Disponível em: <http://revista.ibict.br/ciinf/index.php/ciinf/article/view/146/126. Acessado em 25/09/09 >. Acesso em: 25 nov. 2009.

COOPER, D. R.; SCHINDLER, P. S. Métodos de pesquisa em administração. 7a ed. Porto Alegre: Bookman, 2003

COMBEROUSSE, M. Les nouvelles technologies au service de la litterature grise. Bulletin des Bibliothèques de France, Paris, v. 40, n. 2, p.51-53, 1995.

CORREIA, A. M. R. O papel das bibliotecas digitais de literatura científica cinzenta: os repositórios de eprints na comunicação científica. In: JORNADAS DE BIBLIOTECAS DIGITAIS - JBIDI, 2., 2001, Almagro. Jornadas de Ingenieria del Software e Bases de Dados. Almagro: Universidade de Castilla e la Mancha, 2001.

CORREIA, A. M. R.; BORBINHA, J. Deposit of scientific and technical gray literature in Portugal: a case study. In: INTERNATIONAL CONFERENCE ON ENTERPRISE INFORMATION SYSTEMS (ICEIS), 1., 2001, Setubal. Proceedings... Setubal: ICEIS Press, 2001. p. 8-19.

CORREIA, A. M. R.; NETO, M. C. Repositórios digitais de literatura científica cinzenta: estudo de caso sobre as percepções e atitudes das comunidades científicas da matemática e das ciências agrárias em Portugal. In: CONFERÊNCIA DA ASSOCIAÇÃO PORTUGUESA DE SISTEMAS DE INFORMAÇÃO (CAPSI), 2., 2001, Évora. Actas... Évora, 2001.

CÔRTES, P. L. A Importância da literatura cinzenta disponível na internet para as áreas de ciências contábeis e administração de empresas. Revista 
Brasileira de Gestão de Negócios, São Paulo, SP, v. 8, n. 20, p 13-22, jan/abr. 2006.

2008.

Administração de sistemas de informação. São Paulo: Saraiva,

Revistas científicas eletrônicas on-line e a dinâmica da publicação, divulgação e comunicação científica: um quadro conceitual. 2004. 157 f. Tese (Doutorado) -Escola de Comunicações e Artes, Universidade de São Paulo, São Paulo, 2004.

COSTA NETO, P. L. O. Estatística. $2^{a}$ ed. São Paulo: Edgard Blücher, 2002.

DACOL, M. E.; STOLLENWERK, M. F. L.; DOU, H. Informação para processos de benchmarking: proposta de um modelo para avaliação de fontes de informação. In: WORKSHOP BRASILEIRO DE INTELIGÊNCIA COMPETITIVA E GESTÃO DO CONHECIMENTO, 1., 1999, Rio de Janeiro. Anais eletrônicos... Rio de Janeiro: 1999. Disponível em: <http://abraic.org.br/V2/periodicos teses/ic a28.pdf>. Acesso em: 11 mar. de 2008.

DANCEY, C. P.; REIDY, J. Estatística sem matemática para psicologia. $3 a$ ed. Porto Alegre: Artmed, 2006.

DI CESARE, R; SALA, C.. The use of grey literature in the agricultural economics fields: a quantitative analysis. In: INTERNATIONAL CONFERENCE ON GREY LITERATURE, 2., 1995, Washington. Proceedings... Washington: TransAtlantic, 1995.

DIAS, R. Métricas para Avaliação de Sistemas de Informação. Revista Eletrônica de Sistemas e Informação. Florianópolis, SC, v. 1, n. 1, nov. 2002. Disponível em: <http://revistas.facecla.com.br/index.php/reinfo/article/viewFile/117/pdf $>$. Acesso em: 25 set. 2009.

FONSECA, J. S., MARTINS, G. A. Curso de estatística. $6^{\text {a }}$ ed. São Paulo: Atlas, 1996.

FREITAS H. M.; KLADIS, C. M. Da informação à política informacional das organizações: um quadro conceitual. Revista de Administração Pública RAP/FGV, Rio de Janeiro, RJ, v. 29, n. 3, p. 73-86, jul/set. 1995.

FUNARO, V. M. B. O.; NORONHA, D. P.. Literatura cinzenta: canais de distribuição e incidência nas bases de dados. In: POBLACION, D. A.; WITTER, G. P.; SILVA, J. F. M. Comunicação e produção científica: contexto, indicadores, avaliação. São Paulo: Angellara, 2006. p. 215 234

GHISI, F. A.; FAMÁ, R.; PIMENTA JÚNIOR, T. Uma estratégia didática para o ensino de economia e finanças internacionais. In: SEMINÁRIOS EM ADMINISTRAÇÃO FEA-USP, 5., 2001, São Paulo. Anais... São Paulo, 2001. Disponível

em: 
<http://www.ead.fea.usp.br/Semead/5semead/Ensino/Uma\%20estrat\%E 9gia\%20didatica.pdf>. Acesso em: 25 set. 2009.

HILL, M. M.; HILL, A. Investigação por questionário. 2 .ed. Lisboa: Silabo, 2002.

KIELGAST, S.; HUBBARD, B. A. Valor agregado à informação: da teoria à prática. Ciência da Informação, Brasília, DF, v. 26, n. 3. 1997. Disponível em: $<$ http://revista.ibict.br/ciinf/index.php/ciinf/article/view/382/342>. Acesso em: 25 set. 2009.

MALHOTRA, N. K. et al. Introdução à pesquisa de marketing. São Paulo: Pearson Prentice Hall, 2005.

MIRANDA, C.; MIRANDA, R. A. M. Interdisciplinaridade e métodos de ensino no curso de contabilidade um estudo no Nordeste Paulista. In.: CONGRESSO USP DE CONTROLADORIA E CONTABILIDADE, 6., 2006, São Paulo. Anais... São Paulo, 2006. Disponível em: <http://www.congressousp.fipecafi.org/artigos62006/426.pdf >. Acesso em: 25 set. 2009.

MORESI, E. A. D. Delineando o valor do sistema de informação de uma organização. Ciência da Informação, Brasília, DF, v. 29, n.1, p.14-24, jan/abr. 2000. Disponível em: <http://www.scielo.br/pdf/ci/v29n1/v29n1a2.pdf>. Acesso em: 25 set. 2009.

MORETTIN, P. A.; BUSSAB, W. O. Métodos quantitativos para economistas e administradores. Rio de Janeiro: Atual, 1981.

NEHMY, R. M. Q.; PAIM, I. A desconstrução do conceito de "qualidade da informação". Ciência da Informação, Brasília, DF, v. 27, n. 1, p. 36-45, jan/abr. 1998. Disponível em: $<$ http://www.scielo.br/pdf/ci/v27n1/05.pdf>. Acesso em: 25 set. 2009.

OLIVEIRA, S. M. Fontes de informação utilizadas por executivos. Revista Digital de Biblioteconomia e Ciência da Informação, Campinas, SP, v. 1, n. 2, p. 18-40, jan./jun. 2004.

PACE, A. K. Black, white, and shades of gray (literature) on the web. Computers in Libraries, Medford, NJ, v. 22, n.4, p. 44-47, abril. 2002.

PAIM, I.; NEHMY, R. M. Q.; GUIMARÃES, C. G. Problematização do conceito de "qualidade" da informação. Perspectivas em Ciência da Informação, Belo Horizonte, MG, v. 1, n. 1, p. 111-119, jan/jun. 1996. Disponível em: $<$ http://www.eci.ufmg.br/pcionline/index.php/pci/article/viewFile/8/27>. Acesso em: 25 set. 2009.

PARREIRAS, F. S. et al. Rede CI: colaboração e produção científica em ciência da informação no Brasil. Perspectivas em Ciência da Informação, Belo Horizonte, MG, v.11, n. 3, p. 302-317, set./dez. $2006 . \quad$ Disponível em: <http://www.scielo.br/pdf/pci/v11n3/a02v11n3.pdf>. Acesso em: 25 set. 2009.

PEREZ ÁLVARES-OSSORIO, J. R. Introducción a la información y documentación científica. Madrid: Alhambra, 1988. 
PESTANA, M. H.; GAGEIRO, J. N. Análise de dados para ciências sociais: a complementariedade do SPSS. Lisboa: Silabo, 2000.

RESENDE, Y. Informação para negócios: os novos agentes do conhecimento e a gestão do capital intelectual. Ciência da Informação, Brasília, DF, v. 31, n. 2, p. 120-128, mai/ago. 2002. Disponível em: <http://revista.ibict.br/ciinf/index.php/ciinf/article/view/167/146> . Acesso em: 25 set. 2009.

SIEGEL, G. E. Capturing academic grey literature: starting at home. Publishing Research Quarterly, Ruston, LA, v. 20, n. 1, p. 62-69, mar. 2004.

TARAPANOFF, K., ARAUJO JUNIOR, R. H., CORMIER, P. M. J. Sociedade da informação e inteligência em unidades de informação. Ciência da Informação, DF, v. 29, n. 3, p. 91-100, set/dez. 2000. Disponível <http://revista.ibict.br/ciinf/index.php/ciinf/article/view/231/206> . Acesso em: 25 set. 2009.

WEBSTER, P. Breaking down information silos: integrating online information. ONLINE: Exploring Technology \& Resources for Information Professionals, Medford, NJ, v. 28, n. 6, p. 30-35, nov/dez. 2004.

XIFRA-HERAS, J. A informação cotidiana. In: XIFRA-HERAS, J. A informação. Rio de Janeiro: Lux, $1975 . \quad$ Disponível em: <http://www.portalrp.com.br/bibliotecavirtual/relacoespublicas/teoriaseconceitos/0014.htm $>$. Acesso em: 27 nov. 2007.

ZAMBON, A. C. et al. Validação e fidedignidade de modelos de dinâmica de sistemas. In.: SIMPÓSIO DE ENGENHARIA DE PRODUÇÃO, 13, 2006, Bauru. Anais... Bauru, 2006. Disponível em: <http://www.simpep.feb.unesp.br/anais/anais_13/artigos/403.pdf >. Acesso 25 set. 2009. 